\title{
Effect of Arbuscular Mycorrhizal Fungal Inoculation on Sorghum bicolor Growth at Different Phosphate Levels: A Greenhouse Study
}

Souleymane Koné ${ }^{1}$, Fallaye Kanté ${ }^{1}$, Ibou Diop ${ }^{2,3}$, Fatou Ndoye ${ }^{2,3}$, Abdala Gamby Diédhiou ${ }^{2,3}$, Aboubacry Kane ${ }^{2,}$

${ }^{3}$, Ousmane Sacko ${ }^{1}$ and Inamoud Ibny Yattara ${ }^{1}$

1. Laboratory of Soil Microbiology (LMS), Faculty of Sciences and Technics, University of Sciences Technics and Technologies of Bamako (USTTB), BP E 3206, Mali

2. Department of Biology Vegetable, Faculty of Sciences and Technics, University Cheikh Anta Diop, BP 5005 Dakar-Fann, Senegal

3. Common Laboratory of Microbiology, Development Research Institute, Senegal Agronomic Research Institute, University Cheikh Anta Diop (LCM/IRD/ISRA/UCAD), Dakar, Senegal

\begin{abstract}
In sub-Saharan Africa, Sorghum (Sorghum bicolor) is an important cereal for both human being and animals. Unfortunately, its production is confronted to soils with deficiency of phosphorus. Traditional use of mineral phosphate on this culture fertilization is expensive and may cause contamination. It is thus necessary to seek more efficient and economic reasonable techniques to improve sorghum growth. Arbuscular mycorrhizal fungi (AMF) constitute a reference for phosphorus improvement and plant nutrition. This study aimed to investigate the effects of AMF strains (Rhizophagus irregulare, Glomus aggregatum, G. mosseae) on growth of sorghum cultivated in greenhouse on Sangalkam soil (Senegal) sterilized with or without Tilemsi natural phosphate (PNT). The phosphorus can represent until $0.2 \%$ of the dry weight of the plant. Two fertilizers were used separately and together to doses of $20 \mathrm{~g}$ by strain, $100 \mathrm{mg}$ and $200 \mathrm{mg}$ of PNT. The experiment lasted for $120 \mathrm{~d}$. Results showed that mycorrhizal colonization intensity varied between $40 \%$ and $80 \%$ for all treatments. AMF inoculation increased sorghum plant height and biomass, regardless of PNT amendment. The inoculation permits to bring strain of AMF that intervene efficiently in the transportation and the availability of phosphorus for the plant.
\end{abstract}

Key words: Arbuscular mycorrhizal fungi, Tilemsi natural phosphate, Sorghum bicolor.

\section{Introduction}

In world sorghum (Sorghum bicolor) is the fifth important cereal with a production estimated to 58 million tons in 2004. Its yield reaches 4 tons by hectare in United States of America, against $870 \mathrm{~kg}$ by hectare in Africa, where it is used as food for man and animals, the construction of dwellings and as fuel $[1,2]$.

In sub-Saharan Africa $80 \%$ of soils are nearly involved in assimilated phosphorus [3]. It constitutes plants growth limiting factor [4]. Phosphorus can be

Corresponding author: Souleymane Koné, Ph.D., research field: plant biotechnology. present in important quantity in soil, but largely inaccessible to plants because of its very weak solubility [5].

In Mali sorghum holds a primordial room in populations food, with a production estimated to 650 thousand tons in 2004 [6].

Nowadays cultures intensification is greatly dependent on mineral manures that enrich soils in necessary nourishing elements to the development of plants [7]. However, these products are expensive and inaccessible peasants to weak spending power [8]. An alternative to the use of these manures is the recourse to the microbial biofertilizers [9]. Among these biologic fertilizers, particular attention is 
granted to arbuscular mycorrhizal fungi (AMF) [10], which encourage plants hydromineral nutrition [11]. Inoculation with these fungi strains permits to improve plants growth [12], especially when it is coupled to a phosphatic fertilization [13, 14]. Natural phosphates constitute a potential source of less dear phosphorus for peasants [8]. However, these phosphates used by plants are not always comfortable because of their weak solubility, from where the interest to apply them in combination with AMF strains. Under tropics characterized by a deficit of phosphorus [15], the AMF constitute a natural primordial source of hydromineral nutrition that assures plants growth and health [11, 16]. To this title the AMF are used to increase productions in agriculture, which would reduce the use of chemical fertilizing [17]. This work specifically aimed to value effect of fertilization with AMF strains and natural phosphate on height, biomasses production and mycorrhization (intensity, frequency) of sorghum plants cultivated on pots in greenhouse.

\section{Materials and Methods}

\subsection{Materials}

\subsubsection{Culture Substratum}

Culture soil has been appropriated to Sangalkam/Sénégal. It is a soil poor in assimilated $\mathrm{P}$ (2.1 ppm) [18]. This soil contains besides: $5.40 \%$ of clay, $5.80 \%$ of silt, $88.8 \%$ of sand, $0.60 \%$ of organic matters, $0.30 \%$ of total carbon, $0.02 \%$ of total nitrogen, $14 \%$ of $\mathrm{C} / \mathrm{N}$ ratio, $333.5 \mathrm{ppm}$ of total potassium, $41.4 \mathrm{ppm}$ of total phosphorus, $2.1 \mathrm{ppm}$ of assimilated phosphorus, $1.03 \mathrm{ppm}$ of total calcium, and $0.3 \mathrm{ppm}$ of total magnesium. The $\mathrm{pH}\left(\mathrm{H}_{2} \mathrm{O}\right)$ and the $\mathrm{pH}(\mathrm{KCl})$ are respectively 6 and 4.6.

\subsubsection{Plant Material}

Sorghum seeds (cultivar CSM 63 Jakunbè) coming from FASO KABA/Mali were used. Its cycle is $100 \mathrm{~d}$ and it is cultivated in isohyet of $300-800 \mathrm{~mm}$. Its middle output is $1.5 \mathrm{t} / \mathrm{ha}$ with the loose panicles to grains of white color.

\subsubsection{Arbuscular Mycorrhizal Strains}

Rhizophagus irregular (Ri), Glomus aggregatum (IR-27) and G. mosseae (Gm) were used. They come from the collection of the common laboratory of microbiology of Dakar/Senegal and gave convincing results in several former work [14, 18-23]. This inoculum is constituted of a mixture of spores, hyphes, fragments of root colonized by endomycorrhizal fungi and sands.

2.1.4 Natural Phosphate

The used natural phosphate is Tilemsi natural phosphate (PNT), Mali used under its pulverulente shape and content $30 \%$ of $\mathrm{P}_{2} \mathrm{O}_{5}, 10 \%$ of elements lower to $40 \mu \mathrm{m}, 60 \%$ of elements lower to $60 \mu \mathrm{m}$ and present a solubility of $0.007 \%$ in water [24].

\subsection{Methods}

2.2.1 Culture Soil Sterilization and Pots Replenishment

Culture soil was autoclaved two times to $120{ }^{\circ} \mathrm{C}$ during $20 \mathrm{~min}$. After autoclavage it has been divided on plastic pots of $5.23 \mathrm{~cm}^{3}$, at the rate of $2 \mathrm{~kg}$ by pot.

2.2.2 Seeds Scatting and Plants Thinning

Sorghum seeds were sown to three (3) by pot and germinated on $3 \mathrm{~d}$. One week after seedling, the young plants were unmarried to two (2) by pot, then to one (1) at the 10th day after the seedling.

2.2.3 Setting Up and Conduct of Experimentation

Experimentation has been driven in greenhouse to the LCM. Two factors (inoculation with AMF strains to five modes; fertilization with PNT to three levels) have been studied. Fifteen (15) treatments have been considered: Wetness; Ri; IR-27; Gm; Cocktail; PNT (100 mg); Ri + PNT (100 mg); IR-27 + PNT (100 mg); Gm + PNT (100 mg); Cocktail + PNT (100 mg); PNT (200 mg); Ri + PNT (200 mg); IR-27 + PNT (200 mg); Gm + PNT (200 mg); Cocktail + PNT (200 mg). These treatments were arranged following an uncertain pull. Sixteen (16) pots have been used by treatment.

The inoculum of AMF has been brought at the 
rate of $20 \mathrm{~g} /$ pot at the same time as the PNT during the seedling. Plants were watered regularly with the faucet water. Experimentation lasted four months (120 d).

\subsubsection{Data Collection and Analysis}

Plants height has been measured every $15 \mathrm{~d}$ during $60 \mathrm{~d}$. Mycorhization and biomasses were valued to the 60th and 120th days on eight (8) plants by treatment. Plants were withdrawn of pots. Some fine roots have been taken away, then plants aerial and root parts were separated. Roots were colored according to Philips and Hayman [25] method. The rate of endomycorhization corresponds to the frequency of infection ( $\mathrm{F} \%$ ) that is equal to the number of time that the root is infected and the intensity of mycorhization (I\%) is correspondent to the degree of infection of the root by the fungi, which are valued to the optic microscope by the method of Trouvelot et al. [26]. The degree of endomycorhizal colonization of every fragment is estimated according to a scale constituted of six values corresponding to: $0 \%$, a total absence of infection of the root; $<1 \%$, a root infected with at least a hyphe mycélien; $<10 \%$, some hyphes presence and fungi arbuscules in the root; $<50 \%$, a middle infection of the root with hypheses and especially of arbusculeses; $>50 \%$, a root infected with several bladders and or arbusculeses and hyphae; > 90\%, an overgrown root nearly completely by bladders and/or arbusculeses and hyphae.

Analysis of variance (ANOVA) has been done with the software $\mathrm{R}$ ( $\mathrm{R}$ version $\mathrm{i} 386$ 3.2.2) and the test of Tukey contrasts to the doorstep of $5 \%$ has been used for the comparison of averages.

\section{Results}

\subsection{AMF and PNT Effect on Plants Height and} Biomasses Production

Results present in Table 1 show that to the course of the first three periods (15th, 30th and 45th days) of measure, IR-27 + PNT (100 mg) had a positive effect more marked on plants height with respectively 34.56 ,
66.96 and $86.62 \mathrm{~cm}$. To these same periods the weakest values for this variable were 23.42, 40.07 and $55.32 \mathrm{~cm}$, respectively, for witnesses, Cocktail + PNT (200 mg) and Cocktail.

At the 60th and 120th days of culture a meaningful effect has been noted between the different treatments for biomasses. So at the end of $60 \mathrm{~d}$, Cocktail + PNT (100 mg) with $4.37 \mathrm{~g}$ and IR-27 + PNT (100 mg) with $1.56 \mathrm{~g}$ encouraged respectively production of dry aerial biomass (DAB) and dry root biomass (DRB). To this same period, the weak value for these variables was respectively $1.82 \mathrm{~g}$ and $0.68 \mathrm{~g}$ for IR-27 and witnesses.

At the 120th day, Ri + PNT (200 mg) with $3.71 \mathrm{~g}$ and IR-27 + PNT (100 mg) with $1.74 \mathrm{~g}$ had a positive effect more marked respectively on DAB and DRB production. While to the same period the weakest value for the DAB has been recorded at plants of IR-27 treatment with $1.58 \mathrm{~g}$ and the one of DRB at witnesses with $0.56 \mathrm{~g}$.

\subsection{Effect of Inoculation with AMF in Presence or/No PNT on Plants Mycorhization}

Results gotten to the 60th and 120th days (Table 2) for mycorhization show a meaningful effect between the different treatments. Cocktail + PNT (100 mg) encouraged mycorhization frequency and intensity for respectively $100 \%$ and $76.54 \%$ (Fig. 1a). On the other hand, the weak values of these same variables have been recorded respectively at plants dealt with Cocktail and Cocktail + PNT (200 mg) for respectively $90 \%$ and $47.72 \%$. To the 120 th day, IR-27 + PNT (100 mg), Gm + PNT (100 mg) and Cocktail + PNT (100 mg) with a value of $100 \%$ had a positive effect more marked on mycorrhization frequency, contrary to Cocktail that was less efficient with 93\%. IR-27 + PNT (100 mg) with a value of $77.87 \%$ (Fig. 1b) was more efficient on mycorhization intensity in opposition to Cocktail + PNT (200 mg) that was less efficient on this variable with a value of $50.32 \%$. 
Table 1 Middle value of height $(\mathrm{cm})$ and biomasses $(\mathrm{g})$ of sorghum plants inoculated or/no with arbuscular mycorrhizal fungi (AMF) strains in presence or/no Tilemsi natural phosphate (PNT), measured in different periods.

\begin{tabular}{|c|c|c|c|c|c|c|c|c|}
\hline \multirow{3}{*}{ Treatments } & \multicolumn{8}{|c|}{ Periods of measure and measured variables } \\
\hline & \multirow{2}{*}{ 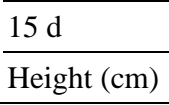 } & \multirow{2}{*}{$\begin{array}{l}30 \mathrm{~d} \\
\text { Height }(\mathrm{cm})\end{array}$} & \multirow{2}{*}{$\begin{array}{l}45 \mathrm{~d} \\
\text { Height }(\mathrm{cm})\end{array}$} & \multirow{2}{*}{$\begin{array}{l}60 \mathrm{~d} \\
\text { Height }(\mathrm{cm})\end{array}$} & \multicolumn{2}{|c|}{$60 \mathrm{~d}$} & \multicolumn{2}{|c|}{$120 \mathrm{~d}$} \\
\hline & & & & & $\mathrm{DAB}(\mathrm{g})$ & DRB (g) & $\mathrm{DAB}(\mathrm{g})$ & DRB (g) \\
\hline T0 & $23.42 \mathrm{a}$ & $44.50 \mathrm{ab}$ & $64.00 \mathrm{ab}$ & 87.06ab & $1.82 \mathrm{a}$ & 0.73absa & $1.96 \mathrm{ab}$ & $0.56 a$ \\
\hline $\mathrm{Ri}$ & 27.28acd & 55.56bd & 71.90ad & 115.56cd & $2.06 \mathrm{a}$ & $0.70 \mathrm{ab}$ & $2.56 \mathrm{ac}$ & $0.62 \mathrm{ab}$ \\
\hline IR-27 & 27.30acd & $54.17 \mathrm{bc}$ & $75.58 \mathrm{bcd}$ & $74.43 a$ & $2.85 \mathrm{ac}$ & $0.76 \mathrm{ab}$ & $1.58 \mathrm{a}$ & 1.33de \\
\hline Gm & 32.12de & $60.20 \mathrm{~cd}$ & 76.05bcd & $105.60 \mathrm{bcd}$ & 3.08ae & $0.94 \mathrm{abc}$ & $3.01 \mathrm{bc}$ & 0.86acd \\
\hline Cocktail & 27.00acd & $53.58 b c$ & $55.32 \mathrm{a}$ & 115.20cd & $3.27 \mathrm{ae}$ & $1.55 \mathrm{~d}$ & $2.66 \mathrm{ac}$ & 0.81 acd \\
\hline PNT (100 mg) & 31.01ce & 59.75cd & 76.38bcd & 104.71bcd & 2.88acd & $1.41 \mathrm{~cd}$ & $2.65 \mathrm{ac}$ & 1.71ace \\
\hline Ri + PNT (100 mg) & 31.53ce & 59.43cd & 84.01cd & 119.37d & 3.82bce & $1.25 \mathrm{bd}$ & 2.71ac & $0.70 \mathrm{ac}$ \\
\hline IR-27 + PNT (100 mg) & $34.56 \mathrm{e}$ & $66.96 \mathrm{~d}$ & 86.62cd & $125.12 d$ & 4.18ce & $1.56 \mathrm{~d}$ & 3.15bc & $1.74 \mathrm{e}$ \\
\hline Gm + PNT (100 mg) & 29.91bce & $53.36 \mathrm{bc}$ & 80.67bcd & $112.53 c d$ & 4.05се & $1.41 \mathrm{~cd}$ & $3.29 \mathrm{c}$ & 1.25 ce \\
\hline Cocktail + PNT (100 mg) & 28.38acd & 55.06bd & 80.36bcd & $120.17 d$ & $4.37 \mathrm{e}$ & 1.17ad & 2.73ac & 1.21bce \\
\hline PNT (200 mg) & 26.27ac & $52.88 \mathrm{bc}$ & $67.65 \mathrm{ac}$ & 92.47 ас & 3.10аe & 1.05ad & 2.66ас & 0.72acd \\
\hline Ri + PNT (200 mg) & 29.13асе & 57.17bd & 88.83d & 116.06cd & 3.72bce & $1.14 \mathrm{bd}$ & $3.71 \mathrm{c}$ & 1.11acd \\
\hline IR-27 + PNT (200 mg) & 32.17de & $60.12 \mathrm{~cd}$ & 78.43bcd & 111.50cd & 3.07ae & 1.02ad & 2.52ac & 1.09acd \\
\hline Gm + PNT (200 mg) & 29.22bce & 58.02cd & 78.08bcd & 127.43d & 4.31de & $1.40 \mathrm{~cd}$ & $2.86 \mathrm{bc}$ & $0.69 \mathrm{ac}$ \\
\hline Cocktail + PNT (200 mg) & 24.53ab & $40.07 a$ & 75.9bcd & $105.45 \mathrm{bcd}$ & 2.43ab & $0.68 \mathrm{a}$ & $2.06 \mathrm{ab}$ & $0.68 \mathrm{ac}$ \\
\hline Probability & 0.001 & 0.001 & 0.001 & 0.001 & 0.001 & 0.001 & 0.001 & 0.001 \\
\hline Significance & HS & HS & HS & HS & HS & HS & HS & HS \\
\hline
\end{tabular}

DAB: dry aerial biomass; DRB: dry root biomass; HS: highly significant.

Each value represents average for eight plants. In the same column values followed with the same letter are not statistically different between them to the doorstep of $5 \%$ according to Tukey contrasts test.

Table 2 Middle value of mycorrhization frequency F (\%) and intensity I (\%) of sorghum plants inoculated or/no with AMF strains in presence or/no PNT, at 60th and 120th days.

\begin{tabular}{|c|c|c|c|c|}
\hline \multirow{3}{*}{ Treatments } & \multicolumn{4}{|c|}{ Periods of growth } \\
\hline & \multicolumn{2}{|c|}{$60 \mathrm{~d}$} & \multicolumn{2}{|c|}{$120 \mathrm{~d}$} \\
\hline & $\mathrm{F}(\%)$ & $\mathrm{I}(\%)$ & $\mathrm{F}(\%)$ & $\mathrm{I}(\%)$ \\
\hline $\mathrm{Ri}$ & $97.75 \mathrm{e}$ & $58.94 c$ & $98 d$ & $61.33 \mathrm{c}$ \\
\hline IR-27 & $98.5 f g$ & $75.23 g$ & $98.75 \mathrm{e}$ & $77.50 \mathrm{i}$ \\
\hline $\mathrm{Gm}$ & $98.25 f$ & $68 \mathrm{e}$ & $98.75 \mathrm{e}$ & $70.40 \mathrm{f}$ \\
\hline Cocktail & $90 a$ & $65.34 d$ & 93a & $66.51 d$ \\
\hline Ri + PNT (100 mg) & $98.75 \mathrm{~g}$ & $58.01 \mathrm{c}$ & $98.75 \mathrm{e}$ & $60.52 c$ \\
\hline IR-27 + PNT (100 mg) & $98.75 \mathrm{~g}$ & $73.15 f$ & $100 \mathrm{f}$ & $77.87 \mathrm{i}$ \\
\hline Gm + PNT (100 mg) & $98.75 \mathrm{~g}$ & $58.05 c$ & $100 f$ & $72.33 g$ \\
\hline Cocktail + PNT (100 mg) & $100 \mathrm{~h}$ & $76.54 \mathrm{~g}$ & $100 f$ & $77.50 \mathrm{i}$ \\
\hline $\mathrm{Ri}+\mathrm{PNT}(200 \mathrm{mg})$ & $95 c$ & $71.89 f$ & $96.87 \mathrm{c}$ & $74.31 \mathrm{~h}$ \\
\hline IR-27 + PNT (200 mg) & $96.25 d$ & $66.26 \mathrm{~d}$ & $98 d$ & $68.79 \mathrm{e}$ \\
\hline Gm + PNT (200 mg) & $96 d$ & $51.50 \mathrm{~b}$ & 98.5de & $54.02 b$ \\
\hline Cocktail + PNT (200 mg) & $92.5 b$ & $47.72 \mathrm{a}$ & $95 b$ & $50.32 \mathrm{a}$ \\
\hline Probability & 0.001 & 0.001 & 0.001 & 0.001 \\
\hline Significance & HS & HS & HS & HS \\
\hline
\end{tabular}

Each value represents the average for eight plantations.

In the same column values followed by the same letter are not statistically different between them to the doorstep of 5\% according to

Tukey contrasts test. 


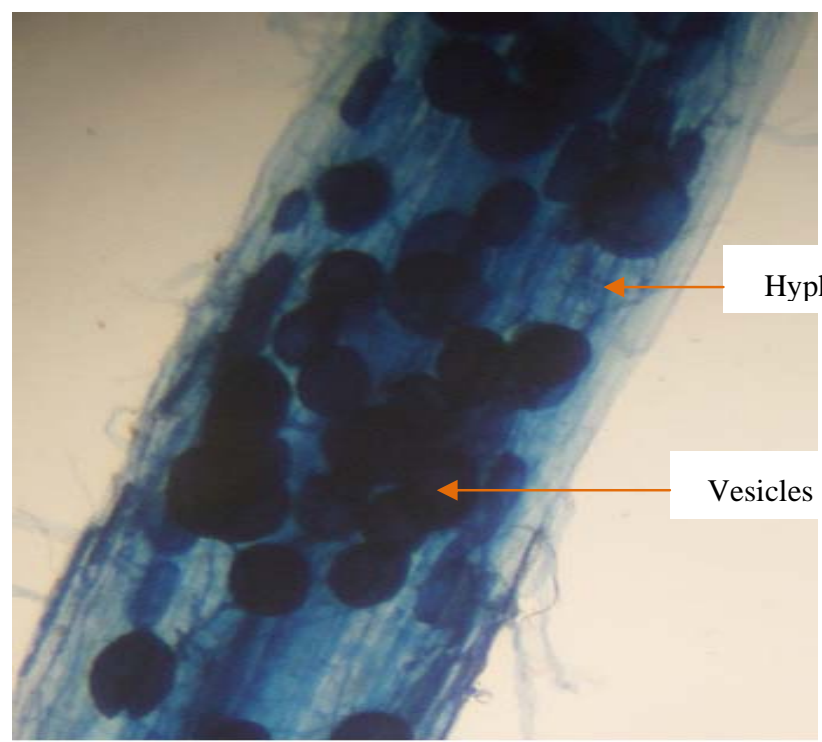

(a)

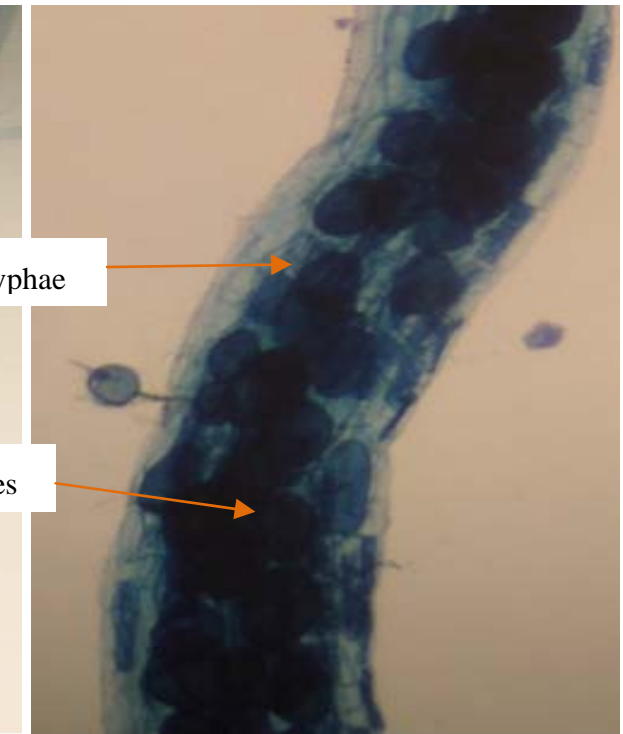

(b)

Fig. 1 Fragment of Cocktail + PNT (100 mg) plant root (a) and fragment of IR-27 + PNT (100 mg) plant root (b).

\section{Discussion}

The inoculation with AMF permitted to get some elevated mycorhization intensity (40\% and 80\%) according to strains. These results agree with those of Diop et al. [18] that found some elevated mycorhization intensity (40\%-65\%) while inoculating with the three strains. The G. mosseae strain proved to be more efficient as for root colonization delay. This result is in harmony with those of Ndoye et al. [27] gotten at Acacia senegal inoculated with this strain and G. aggregatum. However, these results do not corroborate with those of Jansa et al. [28] that found that $R$. irregularis occupied an intermediate position with the middle mycorhization rates. The variation of the mycorhization intensity would be bound very well to differences observed between the used AMF strains, the used plant, to conditions of the middle, at the level of phosphorus in soil and/or to other environmental factories signaled by Boddington and Dodd [29] and Alkan [30]. Values gotten for parameters of growth seem to confirm performances of the used AMF strains. This positive effect of the inoculation gotten with these strains has been demonstrated by several authors $[13,14,18,27]$ that associated mycorrhizal inoculation to phosphatic fertilization to heighten the availability of the phosphorus. These results indicate that the three AMF strains (Ri, Gm and IR-27) stimulated significantly, in presence or/no PNT, height and biomasses sorghum plants in relation to the witness without inoculation. Differences of answer have been noted between strains AMF and have been owed to a functional diversity of these last [31]. These differences are observed among others: in the degree of the root infection [32], the density of the hyphes network to form meetings in complex networks [33], the metabolism and the transfer of the phosphorus toward the plant host by AMF [34] and in short to needs in carbon of the plant host [35].

\section{Conclusions}

Of these results, it comes out again that inoculation with AMF strains in presence of PNT permitted to improve sorghum plants growth. Of this fact, the biologic fertilization to basis of AMF in natural phosphate presence could be counseled in order to improve deficient soil nutrition phosphatic in phosphorus. It is evident from these results that the IR-27 treatment + PNT (100 mg) can be recommended to improve the culture of the sorghum in the field. 


\section{References}

[1] Bazile, D., and Soumare, M. 2004. “Convenient peasants of Variétal Diversity Management in Answer to Ecosystemic Diversity. The Case of Sorghum (Sorghum bicolor (L.) Moench to Mali.” Notebooks Agricultures 13: 480-7.

[2] FAO. 2005. FAO Informatics System on Water and Agriculture. Mali, FAO, Water Earths and Water FAO Welcome, Aquastat, 7.

[3] Bationo, A., Koala, S., and Ayuk, E. 1998. "Soils Fertility for Cereal Production in Sahelo-Soudanian Zone and Natural Phosphate Valorization.” Notebooks Agricultures 7: 365-71.

[4] Smith, S. E., Jakobsen, I., Grønlund, M., and Smith, F. A. 2011. "Roles of Arbuscular Mycorrhizas in Plant Phosphorus Nutrition: Interactions between Pathways of Phosphorus Uptake in Arbuscular Mycorrhizal Roots Have Important Implications for Understanding and Manipulating Plant Phosphorus Acquisition.” Plant Physiology 156: 1050-7.

[5] Schachtman, D. P., Reid, R. J., and Ayling, S. M. 1998. "Phosphorus Uptake by Plants: From Soil to Cell.” Plant Physiol 116: 447-53.

[6] FAOSTAT. 2010. The State of the Food Insecurity in the World: To Fight the Food Insecurity at the Time of the Prolonged Crises. Rome, Italy, 63.

[7] Childers, D. L., Corman, J., Edwards, M., and Elser, J. J. 2011. "Sustainability Challenges of Phosphorus and Food: Solutions from Closing the Human Phosphorus Cycle.” Bio Science 61 (2): 117-24.

[8] Bationo, A., Ayuk, E., Ballo, D., and Koné, M. 1997. "Agronomic and Economic Evaluation of Tilemsi Phosphate Rock in Different Agroecological Zones of Mali.” Nutrient Cycling Agrosyst 48: 179-89.

[9] Fitter, A. 2012. "Why Plant Science Matters?" New Phytologist 193: 1-2.

[10] Pellegrino, E., Turrini, A., Gamper, H. A., Cafa, G., Bonari, E., Young, J. P. W., and Giovannetti, M. 2012. "Establishment, Persistence and Effectiveness of Arbuscular Mycorrhizal Fungal Inoculants in the Field Revealed Using Molecular Genetic Tracing and Measurement of Yield Components." New Phytologist 194: 810-22.

[11] Finlay, R. D. 2008. "Ecological Aspects of Mycorrhizal Symbiosis with Special Emphasis on the Functional Diversity of Interactions Involving the Extraradical Mycelium.” Journal of Experimental Botany 59: 1115-26.

[12] Smith, S. E., and Read, D. J. 2008. Mycorrhizal Symbiosis, 3rd ed. London: Academic Press Inc.

[13] Babana, A. H., and Antoun, H. 2006. "Effect of Tilemsi Phosphate Rock Solubilizing Microorganisms on
Phosphorus-Uptake and Yield of Field Grown Wheat in Mali.” Plant and Soil 287: 51-8.

[14] Sacko, O. 2014. "Valorization of the Phosphate Natural of Tilemsi (PNT) by Mushrooms Endomycorhizienses.” Presented at MSAS Conferences, Bamako, August 03-08, 2014.

[15] Cardoso, I. M., and Kuyper, T. W. 2006. "Mycorrhizas and Tropical Soil Fertility.” Agriculture, Ecosystems and Environment 116: 72-84.

[16] López-Pedrosa, A., González-Guerrero, M., Valderas, A., Azcón-Aguilar, C., and Ferrol, N. 2006. "GintAMTi Encodes a Functional High-Affinity Ammonium Transporter That Is 142 Expressed in the Extraradical Mycelium of Glomus intraradices.” Fungal Genetic Biology 43: 102-10.

[17] Mummey, D. L., Antunes, P. M., and Rillig, M. C. 2009. "Arbuscular Mycorrhizal Fungi Pre-inoculant Identity Determines Community Composition in Roots." Soil Biology \& Biochemistry 41: 1173-9.

[18] Diop, I., Kane, A., Krasova-Wade, T., Sanon, B. K., Houngnandan, P., Neyra, M., and Noba, K. 2013. "Impacts of Pedoclimatics Conditions and Cultural Fashion on the Answer of the Cowpea (Vigna unguiculata L. Walp.) to Inoculation with Endomycorhizal Strain Rhizophagus irregularis." Newspaper Applied of Biosciences 69: 5465-74. ISSN 1997-5902.

[19] Bâ, A., Guissou, T., Duponnois, R., Plenchette, C., Sacko, O., Sidibé, D., Sylla, K., and Windou, B. 2001. "Controlled Mycorhization and N Phosphatic Fertilization: Application to the Domestication of Jujube Tree.”Fruits 56 (4): 261-9.

[20] Asimi, S. 2009. "Influence of Soil Fertility Management Modes on the Microbial Activity in Farming System Long Duration in Burkina Faso.” Ph.D. thesis, Polytechnic University of Bobo-Dioulasso Rural Development Institute, 191. (in French)

[21] Haro, H., Sanon, K. B., Diop, I., Kane, A., Dianda, M., Houngnandan, P., Neyra, M., and Traore, A. 2012. "Answer to the Mycorrhizal Inoculation of Four Varieties of Cowpea (Vigna unguiculata (L.) Walp.) Cultivated in Burkina Faso and Senegal.” Int. J Biol. Chem. Sci. 6 (5): 2097-112. (in Corsican)

[22] Sacko, O., Yattara, I., Messaoud, L., and Neyra, M. 2012. "Effects of a Rock Phosphate on Indigenous Rhizobia Associated with Sesbania sesban.” Journal of Environmental Management 95: 265-8.

[23] Leye, E. H. M., Ndiaye, M., Diouf, M., and Diop, T. 2015. "Comparative Study of Arbuscular Mycorrhizal Fungi Strains Effect on Growth and Mineral Nutrition of Sesame Cultivated in Senegal.” African Crop Science Journal 23 (3): 211-9. (in French) 


\section{Different Phosphate Levels: A Greenhouse Study}

[24] Truong, B., Pichot, J., and Beunard, P. 1977. "Characterization and Comparison of Phosphates Natural Tricalciqueses of Africa of the West in View of Their Direct Use in Agriculture.” Agron. Too Much. 33: 136-45.

[25] Phillips, J., and Hayman, D. 1970. "Improved Procedures for Clearing Roots and Staining Parasitic and Vesicular-Arbuscular Mycorrhizal Fungi for Rapid Assessment of Infection.” Transactions of the British Mycological Society 55 (1): 158-61.

[26] Trouvelot, A., Kough, J. L., and Gianinazzi-Pearson, V. 1986. "Measure of the Mycorhization Rate Goes from a System Radiculaire. Research of Evaluation Methods Having a Functional Significance.” In Mycorrhizae: Physiology Genetics, 1-5.

[27] Ndoye, F., Kane, A., Mangaptché, E. L. N., Bakhoum, N., Sanon, A., Diouf, D., Sy, M. O., Baudoin, E., Noba, K., and Prin, Y. 2012. "Changes in Land Use System and Environmental Factors Affect Arbuscular Mycorrhizal Fungal Density and Diversity, and Enzyme Activities in Rhizospheric Soils of Acacia senegal (L.) Willd.” International Scholarly Research Network, Article ID 563191, doi:10.5402/2012/563191.

[28] Jansa, J., Smith, F. A., and Smith, S. E. 2007. “Are There Benefits of Simultaneous Root Colonization by Different Arbuscular Mycorrhizal Fungi?” New Phytologist 177 (3): 779-89. doi: 10.1111/j.1469-8137.2007.02294.x.

[29] Boddington, C. L., and Dodd, J. C. 2000. "Effect of
Agricultural Practices on the Development of Indigenous Arbuscular Mycorrhizal Fungi. Field Studies in an Indonesian Ultisol.” Plant and Soil 218: 137-44.

[30] Alkan, N., Gadkar, V., Yarden, O., and Kapulnik, Y. 2006. “Analysis of Quantitative Interactions between Two Species of Arbuscular Mycorrhizal Fungi, Glomus mosseae and G. intraradices, by Real-Time PCR." Applied and Environmental Microbiology 72 (6): 4192-9.

[31] Smith, F. A., Jacobsen, I., and Smith, S. E. 2000. "Spatial Differences in Acquisition of Soil Phosphate between Two Arbuscular Mycorrhizal Fungi in Symbiosis with Medicago truncatula.” New Phytologist 147: 357-66.

[32] Hart, M. M., and Reader, R. J. 2002. "Taxonomic Basis for Variation in the Colonization Strategy of Arbuscular Mycorrhizal Fungi.” New Phytologist 153: 335-44.

[33] Avio, L., Pellegrino, E., Bonari, E., and Giovannetti, M. 2006. "Functional Diversity of Arbuscular Mycorrhizal Fungal Isolates in Relation to Extraradical Mycelial Networks.” New Phytologist 172: 347-57.

[34] Boddington, C. L., and Dodd, J. C. 1999. "Evidence That Differences in Phosphate Metabolism in Mycorrhizas Formed by Species of Glomus and Gigaspora Might Be Related to Their Life-Cycle Strategies.” New Phytologist 142: 531-8.

[35] Hart, M. M., and Reader, R. J. 2002. "Host Plant Benefit from Association with Arbuscular Mycorrhizal Fungi: Variation due to Differences in Size of Mycelium.” Biol Fertil Soils 36: 357-66. 